\title{
Avaliação da Perfuração na Soldagem em Operação pelo Processo MIG/MAG de Dutos de Alta Resistência e Baixa Espessura
}

\section{(Evaluation of Burnthrough in the MIG/MAG In-Service Welding of High Strength and Low Thickness Pipelines)}

\author{
Aldo S. Pereira (1), Augusto J. A. Buschinelli (2), Norton Z. Kejelin ${ }^{3}$ \\ ${ }^{1}$ UTFPR, DAMEC,Curitiba,Paraná,Brasil,santos@utfpr.edu.br \\ ${ }^{2} U F S C$, EMC/LABSOLDA, Florianópolis, Santa Catarina, Brasil, buschi@emc.ufsc.br \\ ${ }^{3}$ Faculdade Satc, Departamento de Eng ${ }^{a}$ Mecânica, Criciúma, Santa Catarina, Brasil
}

\begin{abstract}
Resumo
O objetivo deste trabalho foi o desenvolvimento de reparo em dutos com pequena espessura (3,0 e 3,2 mm), fabricados em aços de alta resistência (API 5L X70) e em tubo ASTM 106 Grau B de forma a minimizar o risco de perfuração. Para o experimento, foi construída uma bancada de testes com ajuste variável de vazão e pressão do fluido, a saber, vazões de $20 \mathrm{l} / \mathrm{min}$, $40 \mathrm{l} / \mathrm{min}$ e $80 \mathrm{l} / \mathrm{min}$ e pressões de 2 bar e 5 bar. Foram realizadas soldagens na direção longitudinal sobre tubos contendo água como fluido interno, utilizando-se o processo semiautomático MIG/MAG (GMAW) com posterior avaliação do aspecto da menor penetração do cordão. Desta forma, foram empregadas duas técnicas de soldagem, puxando e empurrando a poça de fusão, assim como os modos de transferência metálica em curto circuito ou em corrente pulsada. No estudo das condições limites para a ocorrência de perfuração foram pesquisados parâmetros de soldagem em função de condições específicas de vazão e de pressão. A temperatura interna da parede da tubulação foi determinada através de uma solução analítica para a transferência de calor na soldagem. Os resultados mostraram que para o processo MIG/ MAG com corrente pulsada e com a técnica empurrando a poça de fusão, mantidas todas as outras variáveis de soldagem fixas, há pequena penetração do cordão de solda. Além disso, os níveis de energia de soldagem para a ocorrência da perfuração revelaram-se superiores aos obtidos na literatura para o processo SMAW, indicando o processo como robusto e apropriado para soldagem de reparo em operação.
\end{abstract}

Palavras-chave: Perfuração, Soldagem em operação, Soldagem MIG/MAG.

\begin{abstract}
The aim of this study was the development of repair procedures to minimize the risk of burn-through in the welding of high strength steels (API 5L X70) and ASTM $106 \mathrm{GrB}$ pipes with low residual thickness (3,0 and $3.2 \mathrm{~mm}$ ). For this purpose, a welding test bench with adjustable water flow and pressure was constructed, that allows the welding of the pipes in longitudinal direction under variable internal fluid pressures (2 and $5 \mathrm{bar}$ ) and flow (20, 40 and $80 \mathrm{l} / \mathrm{min}$.). The semi-automatic MIG/MAG (GMAW)welding process was applied, whereby the conditions for minimizing the penetration under the welding techniques pulling or pushing the weld pool were evaluated, as well as the short-circuit or pulsed current metal transfer modes were investigated. The boundary conditions for burn-through were determined associated to specific levels for water flow and pressure. The internal temperature of the pipe wall was determined by an analytical solution for heat transfer in welding. The results showed that for the pulsed current MIG/MAG and pushing the pool technique, maintaining all other welding variables constant, the weld penetration is reduced. Moreover, the welding power levels for the occurrence of burn-through proved to be superior than those reported in the literature for SMAW, indicating MIG/MAG as a robust and suitable process for in-service welding.
\end{abstract}

Key-words: Burn-through; In-service welding, MIG/MAG Welding.

\section{Introdução}

A soldagem em operação é uma técnica frequentemente empregada no reparo ou modificação de tubulações devido às suas vantagens econômicas, pois evita as perdas oriundas da interrupção do serviço e garante a continuidade no fornecimento do fluido. Na aplicação da técnica, a principal dificuldade

Recebido em 15/02/2013. Texto Final em 01/07/2013.

Trabalho apresentado no CONSOLDA 2012. envolvida é o risco de perfuração da parede do tubo pelo arco voltaico. A tecnologia existente e a experiência adquirida estão relacionadas principalmente com o reparo de tubos de parede espessa (6,3 mm ou mais) e de aços de baixa resistência.

Entretanto é cada vez maior o uso de aços de alta resistência na produção de tubos para a condução de óleo e gás. Ao aumentar o limite de escoamento, a espessura de parede requerida para resistir às pressões internas (ou externas em caso de águas profundas) pode ser reduzida, o que traz como vantagens a diminuição do peso, facilidade na fabricação e montagem, além de requerer menor quantidade de metal de adição e outros consumíveis de soldagem, acarretando menores custos de mão 
de obra. Alternativamente, se pelo contrário maiores espessuras de parede forem mantidas, dutos fabricados com estes aços podem receber maiores pressões de trabalho, resultando em economia na instalação e operação em longas distâncias. Tanto é assim, que a utilização de aços a partir dos graus API 5L X70 e X80 têm dominado o mercado mundial.

Durante a soldagem em operação a grande preocupação é o risco de que o arco elétrico utilizado na soldagem penetre excessivamente através da espessura do tubo e cause uma perfuração e, consequentemente, vazamento do produto. Para que os reparos ocorram em condições seguras, devese especificar um procedimento de soldagem que contemple a seleção do processo e os parâmetros operacionais mais adequados. Como resultado desta seleção, deve ser imposta uma faixa restrita para o aporte térmico, de forma que o alto aporte térmico pode conduzir a perfuração e o baixo aporte térmico traz a possibilidade da ocorrência de trinca a frio.

Não existe uma definição precisa para a perfuração na literatura de soldagem. De acordo com a norma AWS A3.0, que trata dos termos e definições da terminologia da soldagem [1], a perfuração é descrita como uma fusão excessiva ou um orifício. Também define a fusão excessiva como uma cavidade através do metal de solda, usualmente ocorrendo no primeiro passe. Outra definição para perfuração é dada por Adolfsson et al [2]: "ocorre a perfuração na junta soldada ou no metal de solda, quando uma cavidade passante puder ser detectada, iluminando-se a junta pela sua face oposta".

Como principais causas podem-se citar a baixa espessura do duto $(<6,0 \mathrm{~mm})$, o uso de alto aporte de soldagem $(>12,0$ $\mathrm{kJ} / \mathrm{cm}$ ), a oscilação do eletrodo em vez de passe corrido, soldagem na direção longitudinal, uso de eletrodos celulósicos (alta penetração), e uso de eletrodos com diâmetro elevado ( $>3,2$ $\mathrm{mm})$ [3].

Existe controvérsia a respeito da influência do aporte térmico na penetração. De acordo com Bruce [4], a penetração do cordão depende diretamente do aporte térmico proveniente da soldagem. Por outro lado, Pérez et al [5] comprovaram que na soldagem com eletrodos revestidos, a penetração do cordão depende mais especificamente das condições de soldagem do que com o aporte térmico, mostrando uma melhor correlação com o parâmetro $\mathrm{Im}^{1,5} / \mathrm{Vs}^{0,7}$, cujos expoentes foram obtidos experimentalmente.

No programa de análise desenvolvido pelo Instituto Battelle para soldagem em operação [6], o risco de perfuração é avaliado pela temperatura atingida na parede interna do tubo, havendo sido estabelecido, com uma margem de segurança, a temperatura limite de $982^{\circ} \mathrm{C}$ quando são usados eletrodos revestidos de baixo hidrogênio, e $760^{\circ} \mathrm{C}$ para eletrodos celulósicos [7].

Em pesquisa mais recente sobre os procedimentos alternativos para reparo de dutos em operação, Begg [8] mostra que os processos de soldagem semiautomáticos, apesar de sua alta produtividade aliada ao baixo teor de hidrogênio, apresentam como ponto negativo, maior temperatura na parede interna e, por conseguinte, maior risco de perfuração.

Diante desse quadro, o presente trabalho teve como objetivo estabelecer condições de soldagem pelo processo MIG/MAG para reparo em operação de tubulações de pequena espessura, entre 3,0 e 3,2 mm, possibilitando minimizar o risco de perfuração em dadas condições.

\section{Materiais e Métodos}

Para a realização do experimento foram utilizados como materiais de base os tubos ASTM A 106 Grau B e API 5L X70, com diâmetro de 41/2" e espessura de parede de 3,0 $\mathrm{mm}$ e 3,2 mm. Já o metal de adição utilizado foi o arame-eletrodo AWS ER 80S-G.

Utilizando-se o processo de soldagem MIG/MAG, foram avaliados os parâmetros de soldagem, a saber, corrente, tensão, velocidade e energia de soldagem, alterando para tanto, a pressão e vazão do fluido (água). A Figura 1 mostra como foram depositados os cordões de solda sobre o tubo.

Depois de efetuados os cordões de solda sobre a tubulação, estes foram limpos com escova rotativa e inspecionados visualmente quanto ao acabamento superficial.

Após macroscopia dos cordões de solda sobre o tubo foram retiradas duas seções para o mesmo cordão (Figura 1), nas quais foram realizadas as análises macrográficas, fotográficas, de medição do perfil do cordão (penetração, reforço e largura) e de medição da zona afetada pelo calor (ZAC) (Figura 2).

Também foi estimada a temperatura na parede interna do tubo utilizando-se a solução analítica de Santos [9] e realizada uma análise estatística através do programa Minitab para verificar a tendência da penetração em função da corrente (Im) e velocidade (Vs) de soldagem.

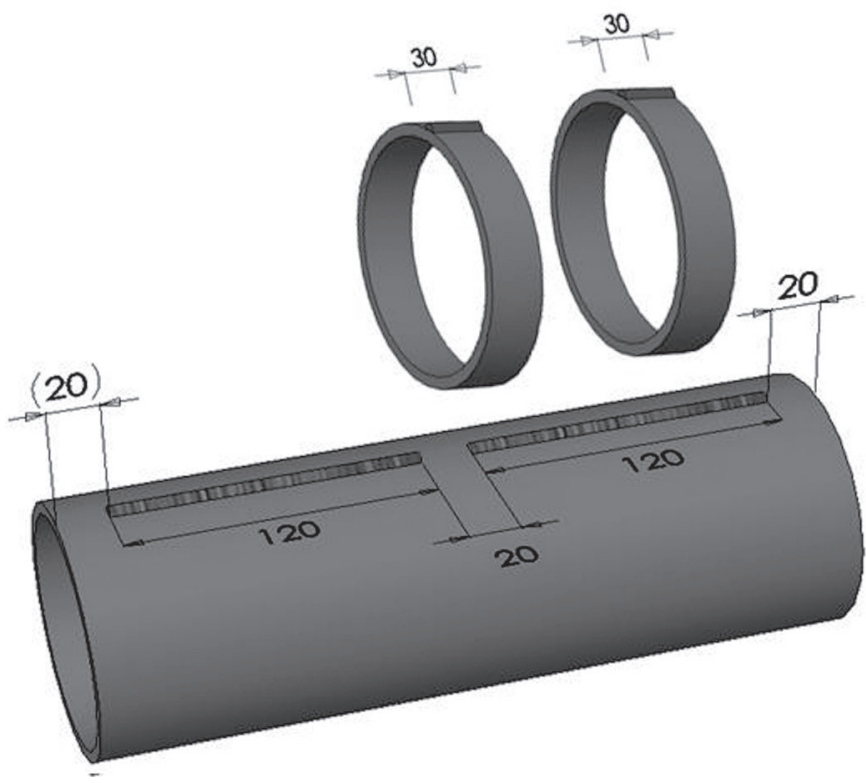

Figura 1. Localizações dos cordões de solda sobre o tubo e corpos de prova para análises

Para a realização desta pesquisa foi projetada e construída uma bancada para testes, conforme mostrado na figura 3 .

Nesta figura (3) são enumerados os principais componentes da bancada, a saber: 1 - Bomba hidráulica centrífuga com três estágios com capacidade: na vazão de 80 1/min. pressão máxima de 2 bar, na vazão até 40 1/min. pressão máxima de 5 bar (fluido água); 2 - Motor elétrico trifásico com 4 CV 2 pólos (3400 rpm); 3 - Reservatório capacidade de 60 litros em aço inoxidável 
(AISI 304) com chicanas para evitar a turbulência do fluido; 4 Rotâmetro Modelo AP-4000, no qual utiliza como fluido a água, que permite medir vazões entre 8,5 a $80 \mathrm{l} / \mathrm{min}$. com resolução de 1 l/min., pressão de 3 bar, podendo operar a uma temperatura de até $60^{\circ} \mathrm{C} ; 5$ - Manômetro marca WIKA que utiliza escala de 0 a 7 bar com subdivisões de 0,1 bar; 6 - Termômetro marca ICEL com temperatura na escala de $-5^{\circ} \mathrm{C}$ a $950^{\circ} \mathrm{C} ; 7$ - Conjunto de válvulas de esferas e tubulações rígidas e flexíveis para a interligação dos componentes; 8 - Flanges e acessórios para a fixação dos tubos a serem soldados; 9 - Mesa e suporte para tubos e acessórios.

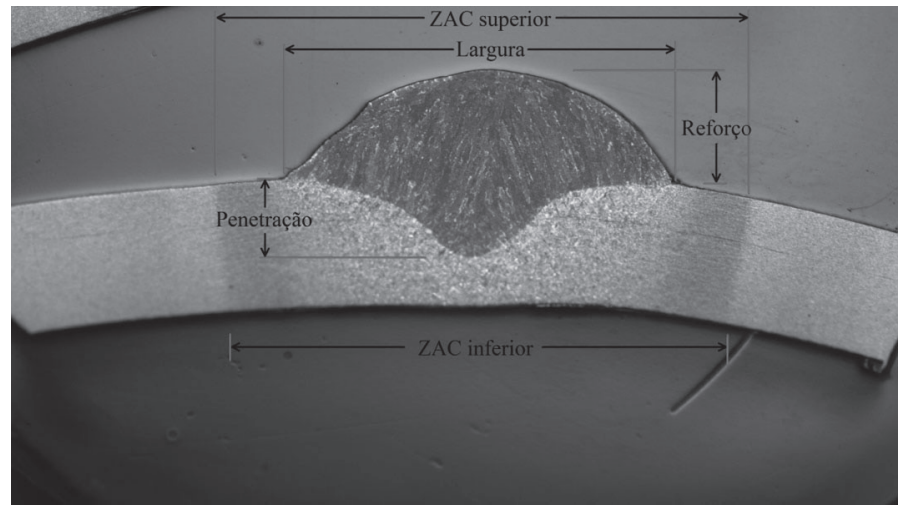

Figura 2. Foto mostrando como medir as dimensões do cordão e da ZAC.

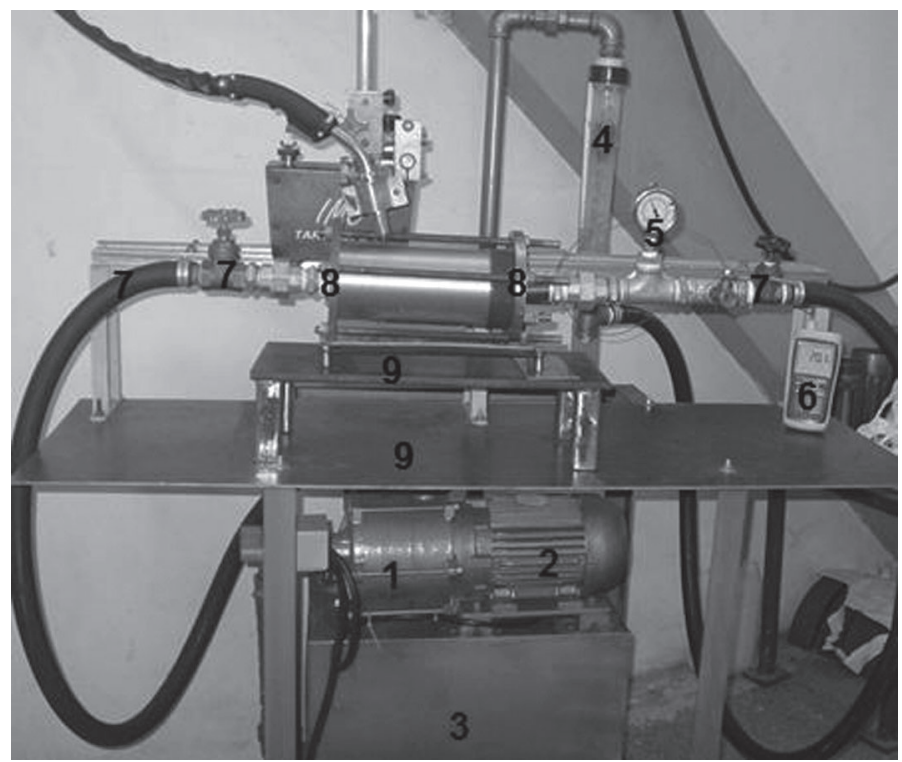

Figura 3. Bancada de teste

Desta forma, foram depositados cordões de solda sobre os tubos ASTM 106 grau B e API 5L X70 na avaliação da perfuração. Para estas classes de aços, as composições químicas são apresentadas na Tabela 1.

Conforme já expresso anteriormente, foi usado para o experimento o metal de adição arame-eletrodo AWS ER 80S$\mathrm{G}$, de forma que sua composição química é fornecida pelo fabricante do consumível, apresentada na Tabela 2.
Tabela 1. Composições químicas dos tubos.

\begin{tabular}{|c|c|c|c|c|}
\hline \multirow{2}{*}{ Elemento } & $\begin{array}{c}(*) \% \mathrm{Em} \\
\text { peso }\end{array}$ & Analisado & $\begin{array}{c}\% \mathrm{Em} \\
\text { peso }\end{array}$ & Norma \\
\cline { 2 - 5 } & $\begin{array}{c}106 \\
\text { Grau B }\end{array}$ & X70 & $\begin{array}{c}106 \mathrm{Grau} \\
\text { B }\end{array}$ & X70 \\
\hline Carbono & 0,228 & 0,088 & máx. 0,24 & máx. 0,22 \\
Manganês & 0,515 & 1,397 & máx. 1,20 & máx. 1,65 \\
Fósforo & 0,001 & 0,015 & máx. 0,025 & máx. 0,025 \\
Enxofre & 0,016 & 0,004 & máx. 0,015 & máx. 0,015 \\
Cromo & 0,044 & 0,023 & & \\
Níquel & 0,070 & 0,016 & & \\
Cobre & 0,023 & 0,016 & & \\
\hline
\end{tabular}

(*) Espectrometria de emissão ótica, $\mathrm{CE}_{\text {(IIW) }} 106$ Grau B = $0,336, \mathrm{CE}_{\text {(IIW) }} \mathrm{X}-70=0,328$.

Tabela 2. Composição química do arame AWS ER 80S-G

\begin{tabular}{|c|c|c|}
\hline Elemento & $\begin{array}{c}(*) \% \text { Em peso / } \\
\text { Analisado }\end{array}$ & \% Em peso / Norma \\
\hline Carbono & 0,074 & \\
Manganês & 1,350 & \\
Silício & 0,750 & Não Especificada \\
Fósforo & 0,013 & \\
Enxofre & 0,012 & \\
Cromo & 0,028 & \\
Molibdênio & 0,470 & \\
\hline
\end{tabular}

$(*)$ Valores obtidos no certificado da qualidade do fornecedor

$$
\text { KESTRA. } \mathrm{CE}_{(\mathrm{IIW})}=0,413 \text {. }
$$

O processo de codificação dos corpos de prova foi realizado conforme as condições em que foi realizada a soldagem, a saber, vazão, pressão e processo de soldagem. As condições nas quais ocorreu a soldagem são mostradas na Tabela 3 e numeradas conforme a representação esquemática mostrada na Figura 4.

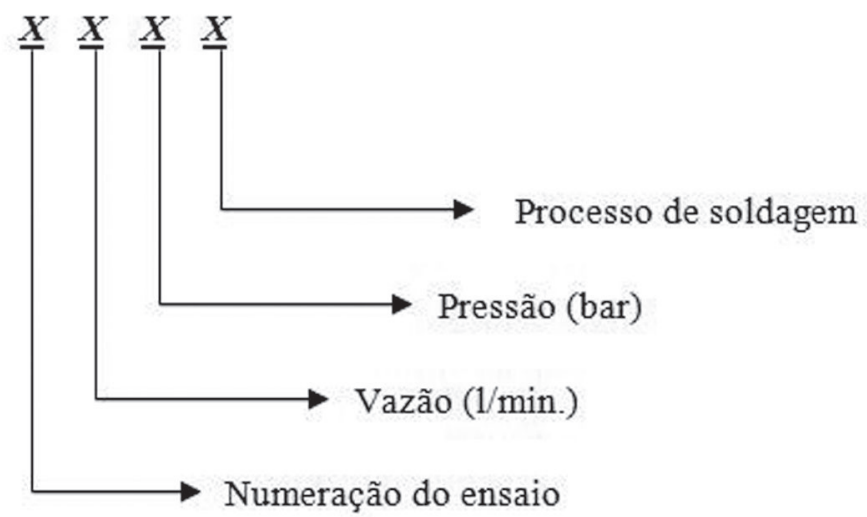

Figura 4. Representação esquemática do processo de codificação dos corpos de prova 
Tabela 3. Codificação dos ensaios realizados.

\begin{tabular}{|c|c|c|c|c|}
\hline Código & Designação & Fluído & Pressão & Vazão \\
\hline 2 & Vazão & água & $\mathrm{X}$ & 20 1/min. \\
\hline 4 & Vazão & água & $\mathrm{X}$ & 40 1/min. \\
\hline 8 & Vazão & água & $\mathrm{X}$ & 80 1/min. \\
\hline 2 & Pressão & água & 2 bar & $\mathrm{X}$ \\
\hline 5 & Pressão & água & 5 bar & $\mathrm{X}$ \\
\hline 0 & Vazão & água & $\mathrm{X}$ & 0 \\
\hline 0 & Pressão & água & 0 & $\mathrm{X}$ \\
\hline
\end{tabular}

\section{Resultados e Discussão}

\subsection{Avaliação da penetração da solda com o processo MIG/ MAG-P (em função da inclinação da tocha)}

Dentre os tipos de transferência metálica para o processo MIG/MAG, a saber, curto-circuito, globular, pulsada e spray, após longa pesquisa [11] com relação ao melhor desempenho em relação à menor penetração, concluiu-se que o processo MIG/ MAG-P é o mais adequado para a avaliação da perfuração na soldagem em operação.

Foram executados ensaios preliminares para a verificação da penetração do cordão de solda em função da inclinação da tocha para o processo de soldagem MIG/MAG-P. Os resultados da penetração do cordão de solda com as técnicas puxando e empurrando, podem ser vistos nas Tabelas 4 e 5, que também mostra os parâmetros de soldagem empregados.

Através de macrografia realizada (Figura 5) pode-se depreender que os perfis dos cordões são distintos. Assim, observa-se que o perfil do cordão da foto A (empurrando a poça de fusão) em comparação com o cordão da foto B (puxando) apresenta menor penetração, maior largura e menor reforço em função de possuir melhor molhabilidade.

Desta forma, na técnica de soldagem com a tocha empurrando a poça de fusão ocorre maior sobreposição da poça e, portanto, diminui a penetração do cordão de solda.

O gráfico da Figura 6 mostra o efeito da corrente sobre a penetração com a tocha puxando e empurrando a poça de fusão para uma velocidade de soldagem de $25 \mathrm{~cm} / \mathrm{min}$. O gráfico foi obtido através de regressão linear múltipla, fixando-se a velocidade de soldagem em $25 \mathrm{~cm} / \mathrm{min}$. e variando-se a corrente de soldagem de 40 a 120A. O resultado mostra que se utilizando a tocha empurrando à poça de fusão, mantidas todas as outras variáveis de soldagem fixas, a penetração do cordão de solda é menor. Esta condição é propícia para a soldagem de reparo de dutos em operação com menor espessura, para minimizar o efeito da perfuração. Este fato ocorre, provavelmente, devido ao efeito de a maior parte do arco incidir em cima das gotas provenientes do metal de adição, reduzindo desta maneira a penetração. Por outro lado, com a tocha puxando a poça de fusão, o arco incide em maior proporção no metal base, aumentando-se, desta forma, a penetração.

Tabela 4. Parâmetros de soldagem e perfis dos cordões de solda com MIG/MAG-P e técnica empurrando em tubo ASTM A 106 Grau B.

\begin{tabular}{|c|c|c|c|c|c|c|c|}
\hline 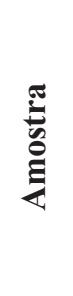 & 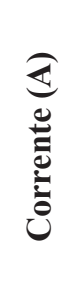 & 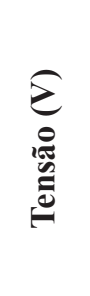 & 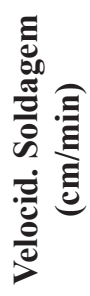 & 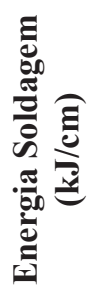 & 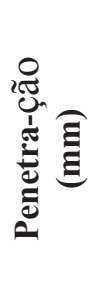 & 异 & 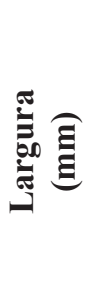 \\
\hline $1 \mathrm{E}$ & 75 & 23,7 & 25 & 4,27 & 1,02 & 1,98 & 6,61 \\
\hline $2 \mathrm{E}$ & 75 & 24,5 & 18 & 6,12 & 1,47 & 2,6 & 8,22 \\
\hline $3 \mathrm{E}$ & 110 & 27,3 & 25 & 7,21 & 1,79 & 2,15 & 9,44 \\
\hline $4 \mathrm{E}$ & 100 & 27,4 & 20 & 8,23 & 2,05 & 2,26 & 9,78 \\
\hline $5 \mathrm{E}$ & 50 & 20,9 & 30 & 2,09 & 0,28 & 1,7 & 3,94 \\
\hline $6 \mathrm{E}$ & 75 & 22,7 & 32 & 3,19 & 1,07 & 1,85 & 5,99 \\
\hline $7 \mathrm{E}$ & 75 & 23,8 & 25 & 4,27 & 0,94 & 1,94 & 6,86 \\
\hline $8 \mathrm{E}$ & 75 & 23,8 & 25 & 4,27 & 1,13 & 2,02 & 6,61 \\
\hline $9 \mathrm{E}$ & 75 & 23,4 & 25 & 4,21 & 0,98 & 1,92 & 6,58 \\
\hline $10 \mathrm{E}$ & 50 & 19,8 & 20 & 2,97 & 0,64 & 2.30 & 4,90 \\
\hline $11 \mathrm{E}$ & 100 & 26,6 & 30 & 5,32 & 1,32 & 2,05 & 7,82 \\
\hline $12 \mathrm{E}$ & 40 & 21,4 & 25 & 2,05 & 0,23 & 1,75 & 3,54 \\
\hline $13 \mathrm{E}$ & 75 & 24,1 & 25 & 4,34 & 0,83 & 1,98 & 6,69 \\
\hline
\end{tabular}




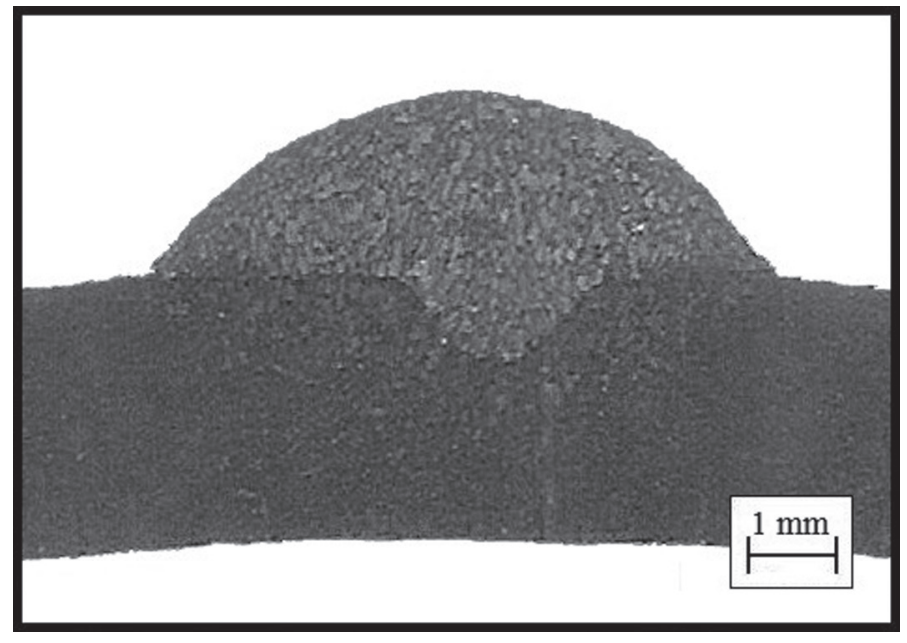

Foto $A\left(\operatorname{Im}=75 \mathrm{~A} ; V_{S}=25 \mathrm{~cm} / \mathrm{min}\right.$;

$E s=4,2 \mathrm{~kJ} / \mathrm{cm} ; P=1,0 \mathrm{~mm})$

Foto A-técnica empurrando

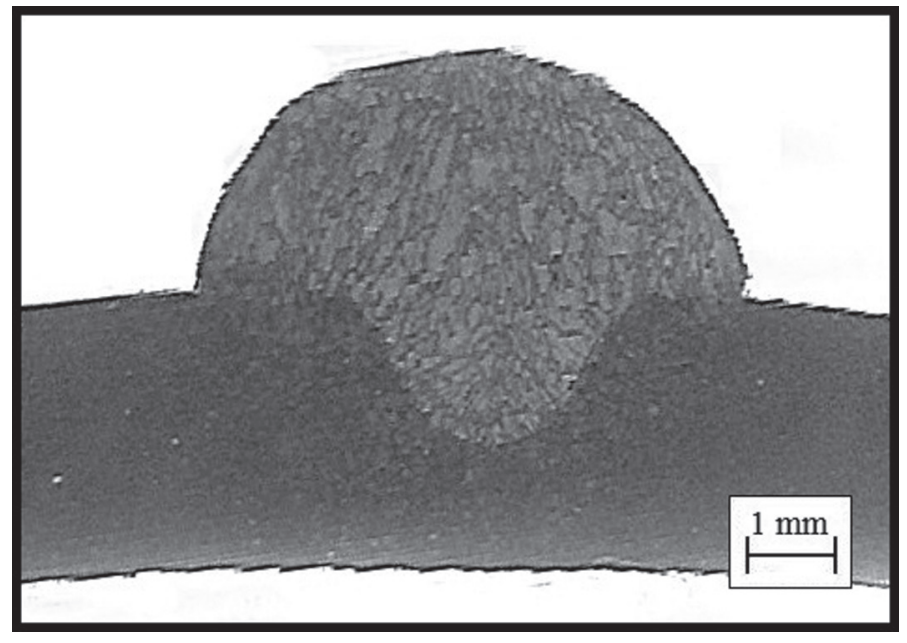

Foto $B\left(\operatorname{Im}=75 \mathrm{~A} ; V_{S}=25 \mathrm{~cm} / \mathrm{min}\right.$; $E s=4,2 \mathrm{~kJ} / \mathrm{cm} ; P=1,8 \mathrm{~mm})$

Foto $B$-técnica puxando

Figura 5. Macrografia com os mesmos parâmetros de soldagem.

Tabela 5. Parâmetros de soldagem e perfis dos cordões de solda com MIG/MAG-P e técnica puxando em tubo ASTM A 106 Grau B

\begin{tabular}{|c|c|c|c|c|c|c|c|}
\hline 焉 & 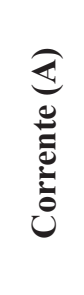 & 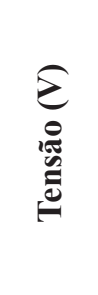 & 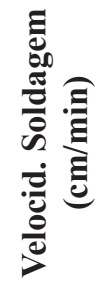 & 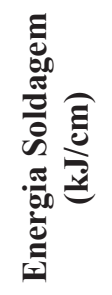 & 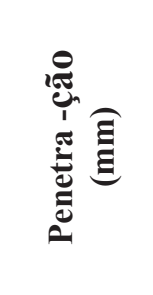 & 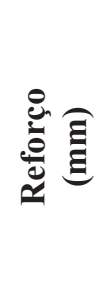 & 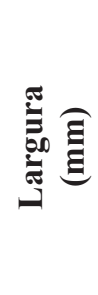 \\
\hline $1 \mathrm{P}$ & 75 & 23,3 & 25 & 4,20 & 1,85 & 2,62 & 6,16 \\
\hline $2 \mathrm{P}$ & 75 & 23,2 & 18 & 5,80 & 2,66 & 2,94 & 7,95 \\
\hline $3 \mathrm{P}$ & 110 & 26,6 & 25 & 7,03 & Perfurou & & \\
\hline $4 \mathrm{P}$ & 100 & 26,5 & 20 & 7,96 & Perfurou & & \\
\hline $5 \mathrm{P}$ & 50 & 20,9 & 30 & 2,09 & 0,66 & 2,32 & 3,31 \\
\hline $6 \mathrm{P}$ & 75 & 23,4 & 32 & 3,29 & 1,32 & 2,54 & 6,36 \\
\hline $7 \mathrm{P}$ & 75 & 23,5 & 25 & 4,24 & 1,17 & 2,58 & 6,36 \\
\hline $8 \mathrm{P}$ & 75 & 23,0 & 25 & 4,15 & 1,45 & 2,47 & 6,41 \\
\hline $9 \mathrm{P}$ & 75 & 23,3 & 25 & 4,20 & 1,47 & 2,64 & 7,05 \\
\hline $10 \mathrm{P}$ & 50 & 20,5 & 20 & 3,03 & 0,89 & 2.73 & 4,62 \\
\hline $11 \mathrm{P}$ & 100 & 26,2 & 30 & 5,24 & 1,60 & 2,51 & 8,35 \\
\hline $12 \mathrm{P}$ & 40 & 22,4 & 25 & 2,15 & 0,55 & 2,77 & 2,81 \\
\hline $13 \mathrm{P}$ & 75 & 22,8 & 25 & 4,11 & 1,62 & 2,37 & 6,48 \\
\hline
\end{tabular}




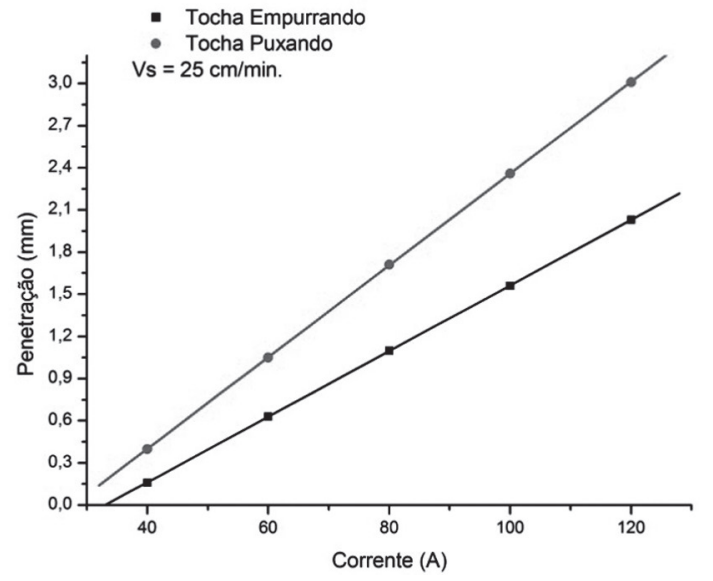

Figura 6. Gráfico do efeito da corrente sobre a penetração na velocidade de soldagem de $25 \mathrm{~cm} / \mathrm{min}$.

\subsection{Avaliação da penetração na Soldagem MIG/MAG-P e Curto circuito, espessura $3,2 \mathrm{~mm}$ e velocidade soldagem de $30 \mathrm{~cm} / \mathrm{min}$.}

Os resultados obtidos mostram os valores de Im e Es (Tabela 7) para os quais ocorreu a perfuração na soldagem com MIG/ MAG com imposição de tensão em curto circuito.

Tabela 7. Valores de Im e Es para furar durante a soldagem MIG/MAG - curto circuito em tubo API 5L X70.

\begin{tabular}{|c|c|c|}
\hline Condição: pressão e vazão & $\operatorname{Im}(\mathrm{A})$ & Es $(\mathrm{kJ} / \mathrm{cm})$ \\
\hline 800 & $>204,9$ & $>9,02$ \\
\hline 622 & $>180,8$ & $>7,56$ \\
\hline 525 & $>184,3$ & $>7,68$ \\
\hline 542 & $>184,0$ & $>7,72$ \\
\hline 445 & $>174,5$ & $>6,72$ \\
\hline 782 & $>200,7$ & $>8,80$ \\
\hline
\end{tabular}

A pior condição encontrada para a ocorrência do furo foi para 445 , ou seja, para a vazão de $40 \mathrm{l} / \mathrm{min}$. e pressão de 5 bar, com Im acima de 174,5 A e Es maior que $6,72 \mathrm{~kJ} / \mathrm{cm}$. Apesar de o tubo apresentar maior espessura $(3,2 \mathrm{~mm})$ do que no experimento que utilizou a técnica empurrando a poça de fusão $(3,0 \mathrm{~mm})$, os valores de $\operatorname{Im}(174,5 \mathrm{~A})$ e Es $(6,72 \mathrm{~kJ} / \mathrm{cm})$ são menores para furar do que no experimento empurrando a poça de fusão. Portanto, a soldagem com MIG/MAG em curto circuito apresenta comportamento desfavorável em relação ao pulsado, tratando-se da penetração do arco. $\mathrm{O}$ resultado encontrado em todos os casos sobre o melhor comportamento do arco, em relação ao furo, foi para 782 , ou seja, com vazão de 80 1/min. e sob pressão de 2 bar.

Da mesma forma, foram executadas soldagens com o processo MIG/MAG-P e espessura de parede 3,2 $\mathrm{mm}$. A Tabela 8 mostra os valores de Im e Es em função das condições de vazão e pressão no qual ocorreu o furo. Novamente, a pior condição encontrada de perfuração foi também para 114 5, ou seja, com a vazão de 40 l/min. e sob pressão de 5 bar, com Im acima de
200 A e Es maior que $12,5 \mathrm{~kJ} / \mathrm{cm}$. Ao aumentar a pressão do fluido, espera-se que a corrente limite para ocorrer a perfuração diminua. Entretanto, o valor limite da corrente não variou com a vazão como era esperado e, além disso, o valor da corrente limite ao soldar sem vazão no interior do tubo foi menor que ao ter vazão.

Os altos valores encontrados de Im e Es para que ocorra a perfuração com a soldagem MIG/MAG-P, mostram que esse processo é o mais adequado para a soldagem em operação de dutos, uma vez que haverá a perfuração (furo) em valores de corrente e tensão superiores à outros processos estudados, denotando maior segurança quando da soldagem em operação. Este resultado é promissor em se tratando de um processo de soldagem semiautomático com alta produtividade e de baixíssimo teor de hidrogênio. Outro resultado interessante foi observado na perfuração do arco que ocorreu com alta energia de soldagem $(12,5 \mathrm{~kJ} / \mathrm{cm})$. Para condição semelhante de espessura utilizando-se o processo de eletrodo revestido, a recomendação encontrada na literatura [6] é utilizar a máxima energia de 8,7 $\mathrm{kJ} / \mathrm{cm}$.

No uso do processo de soldagem MIG/MAG, as piores condições apresentadas para a ocorrência do furo foram observadas com a pressão de 5 bar, sendo esta a maior pressão alcançada durante os testes. Ao contrário, as melhores condições encontradas foram observadas com vazão de $80 \mathrm{l} / \mathrm{min}$., sendo esta a maior vazão de água alcançada durante os testes. Quanto maior a vazão no interior do tubo, maior é a troca térmica na parede do tubo e assim, menor será a penetração da solda.

Tabela 8. Valores de Im e Es para furar durante a soldagem MIG/MAG-P em tubo API 5L X70.

\begin{tabular}{|c|c|c|c|}
\hline Condição: pressão e vazão & $\operatorname{Im}(\mathrm{A})$ & $\operatorname{Ief}(\mathrm{A})$ & Es $(\mathrm{kJ} / \mathrm{cm})$ \\
\hline 1200 & $>210$ & $>227$ & $>13,5$ \\
\hline 1522 & $>240$ & $>251$ & $>16,2$ \\
\hline 1225 & $>210$ & $>227$ & $>13,8$ \\
\hline 1442 & $>230$ & $>242$ & $>15,7$ \\
\hline 1145 & $>200$ & $>220$ & $>12,5$ \\
\hline 1682 & $>250$ & $>255$ & $>17,7$ \\
\hline
\end{tabular}

3.3. Comportamento da penetração no processo de soldagem MIG/MAG em corrente pulsada empurrando a poça de fusão.

Após uma longa pesquisa sobre qual o melhor desempenho em relação à menor penetração obtida com o processo MIG/ MAG, os resultados demonstraram que o processo MIG/MAG em corrente pulsada e empurrando a poça de fusão é o melhor.

Assim, com este processo de soldagem foram executados ensaios nas condições mais severas obtidas nos resultados anteriores, a saber, quando da ocorrência de perfuração com vazão de 40 l/min. e com pressão de 5 bar.

Os resultados da penetração dos cordões de solda com o processo MIG/MAG em corrente pulsada empurrando a poça de fusão, além dos parâmetros de soldagem obtidos, podem ser observados na Tabela 9. 
Os resultados foram processados estatisticamente através do programa Minitab para se verificar o comportamento da penetração do cordão de solda em função da corrente e da velocidade de soldagem, cujo resultado do projeto de superfície de resposta " 22 total" (2 fatores: Im e Vs; 2 níveis: 120 e 180 A para corrente média, 25 e $35 \mathrm{~cm} / \mathrm{min}$. para velocidade de soldagem) é mostrado na Tabela 9.

A equação 1 expressa a penetração $(\mathrm{P})$ do cordão de solda em função da Corrente (Im) e velocidade de soldagem (Vs), sendo obtida, para tanto, através de regressão linear múltipla pelo método da superfície de resposta.

$\mathrm{P}=-9,2115+0,0189(\mathrm{Im})+0,6147(\mathrm{Vs})$

- 0,0097(Vs)2-0,0004(Im*Vs).

Analisando-se o gráfico da superfície de resposta da figura
7, para o processo MIG/MAG-P empurrando com simples deposição sobre tubos API 5L X70 com vazão de 40 1/min. de água e pressão de 5 bar, pode-se retirar as seguintes informações: - A penetração aumenta com o aumento da corrente. A influência da corrente é maior para baixas velocidades de soldagem.

- Para o intervalo pesquisado de velocidade de soldagem, entre 25 a $35 \mathrm{~cm} / \mathrm{min}$., e para o intervalo de corrente entre 120 a $180 \mathrm{~A}$, a penetração aumenta com o aumento da velocidade de soldagem até o valor aproximado de $30 \mathrm{~cm} / \mathrm{min}$. A ocorrência de aumentar a penetração com o aumento da velocidade de soldagem deve-se ao efeito da sobreposição da poça de fusão. Por outro lado, quando a velocidade de soldagem é superior a $30 \mathrm{~cm} / \mathrm{min}$, a penetração diminui com o aumento da velocidade de soldagem. Nesta condição o efeito que prevalece é o efeito da energia de soldagem. Portanto, a velocidade de soldagem tem um ponto de máxima penetração em torno de $30 \mathrm{~cm} / \mathrm{min}$

Tabela 9. Parâmetros de soldagem e perfis dos cordões de solda com processo MIG/MAG em corrente pulsada e empurrando a poça, tubo API-5L X70 espessura 3,2 mm, ER 80S-G.

\begin{tabular}{|c|c|c|c|c|c|c|c|}
\hline 㺃 & 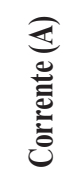 & 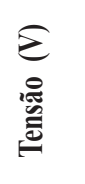 & 造总 & 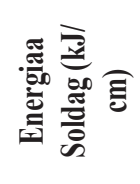 & 䒿 & 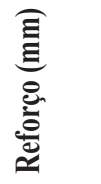 & 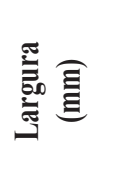 \\
\hline $1 \mathrm{G}$ & 150 & 27,4 & 30 & 9,16 & 1,58 & 2,13 & 10,30 \\
\hline $2 \mathrm{G}$ & 150 & 25,9 & 23 & 11,43 & 1,28 & 2,34 & 11,69 \\
\hline $3 \mathrm{G}$ & 150 & 25,8 & 30 & 8,74 & 1,55 & 2,18 & 10,40 \\
\hline $4 \mathrm{G}$ & 120 & 24,4 & 35 & 5,95 & 1,02 & 2,00 & 7,54 \\
\hline $5 \mathrm{G}$ & 180 & 28,4 & 25 & 13,32 & 1,62 & 2,54 & 13,24 \\
\hline $6 \mathrm{G}$ & 150 & 27,1 & 30 & 9,10 & 1,52 & 1,96 & 10,95 \\
\hline $7 \mathrm{G}$ & 120 & 25 & 25 & 8,62 & 1,24 & 1,92 & 9,94 \\
\hline $8 \mathrm{G}$ & 150 & 26,9 & 37 & 7,36 & 0,95 & 2,02 & 8,34 \\
\hline $9 \mathrm{G}$ & 180 & 30,9 & 35 & 10,22 & 1,17 & 2,38 & 10,14 \\
\hline $10 \mathrm{G}$ & 108 & 23,3 & 30 & 6,14 & 1,19 & 1,77 & 8,93 \\
\hline $11 \mathrm{G}$ & 150 & 25,1 & 30 & 8,56 & 1,54 & 2,18 & 10,40 \\
\hline $12 \mathrm{G}$ & 192 & 28,1 & 30 & 11,54 & 2,07 & 2,45 & 12,81 \\
\hline $13 \mathrm{G}$ & 150 & 26 & 30 & 8,80 & 1,53 & 2,15 & 10,62 \\
\hline
\end{tabular}

\section{Penetração vs Corrente; Velocidade de soldagem}

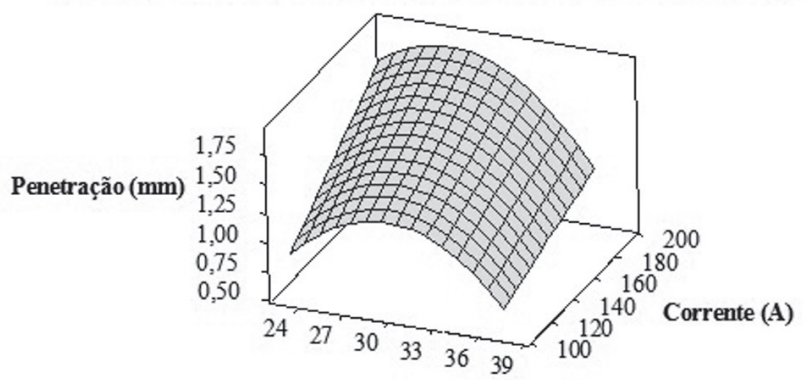

Velocidade de sold agem (cm/min.)

Figura 7. Gráfico da superfície de resposta da penetração versus corrente e velocidade de soldagem para o processo

MIG/MAG-P empurrando a poça de fusão com simples deposição sobre tubos API 5L X70 com vazão de 40 1/min. de água e pressão de 5 bar.
O ensaio macrográfico (Figura 8) não revelou descontinuidades, nem penetração excessiva e/ou perfuração. Observou-se uma pequena deflexão radial na parede interna do tubo, especificamente na amostra $12 \mathrm{G}$, considerada insignificante frente aos dados obtidos. A maior penetração (2,1 mm) ocorreu na soldagem com corrente de 192 A e velocidade de soldagem de $30 \mathrm{~cm} / \mathrm{min}$. (Figura 8, amostra $12 \mathrm{G}$ ).

Depreende-se da figura 8 que o perfil de penetração dos cordões é o perfil fingershape (forma de dedo), típico da soldagem $\mathrm{MIG} / \mathrm{MAG}$ com gás de proteção rico em argônio.

Insta ressaltar que este perfil de penetração não é ideal para a soldagem mutipasses, contudo, não foi utilizada a soldagem multipasses para a obtenção dos resultados da pesquisa apresentada.

Aplicando-se o programa de computador desenvolvido por Santos [9] foram determinadas as temperaturas internas da parede 
da tubulação através da solução analítica para a transferência de calor na soldagem. A tabela 10 mostra os valores obtidos da eficiência térmica (h), da distribuição do fluxo de calor (s) e da temperatura da parede interna, na condição de soldagem com o processo MIG/MAG-P empurrando a poça de fusão em tubos API 51 X70 com espessura de 3,2 mm. Durante a soldagem, o tubo foi pressurizado com pressão de 5 bar e vazão de 40 1/min. de água.

O valor da temperatura na parede interna calculado através da equação analítica de Santos foi similar ao valor encontrado por meio de termopar instalado no tubo. Esta verificação foi efetuada no mestrado do Pérez [5]. Portanto, pode-se admitir que os valores de temperatura apresentados na Tabela 10 são confiáveis.

Os valores da eficiência térmica parecem baixos quando comparados àqueles determinados por vários autores para o processo de soldagem MIG/MAG aplicados em condições normais (peça em contato com o ar ambiente). Entretanto, como neste caso o fluido transfere calor pelo tubo, o ajuste do modelo analítico é feito supondo-se que há uma menor eficiência na

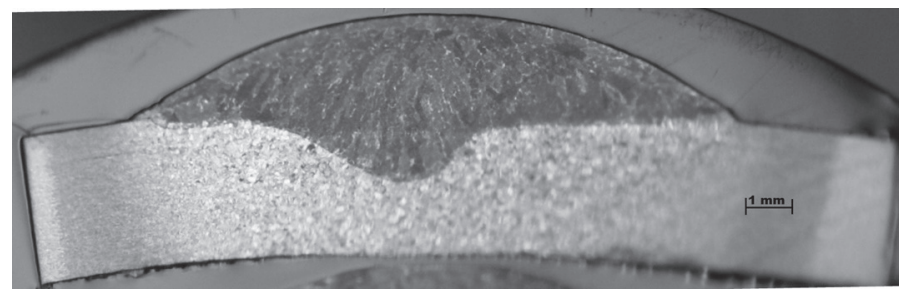

$1 \mathrm{G}$

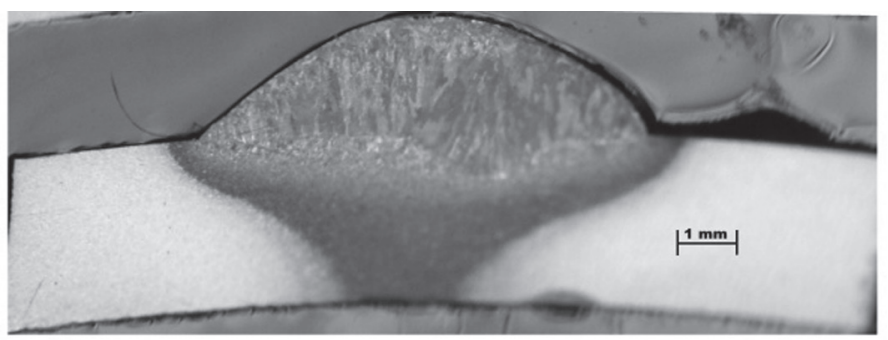

$4 \mathrm{G}$

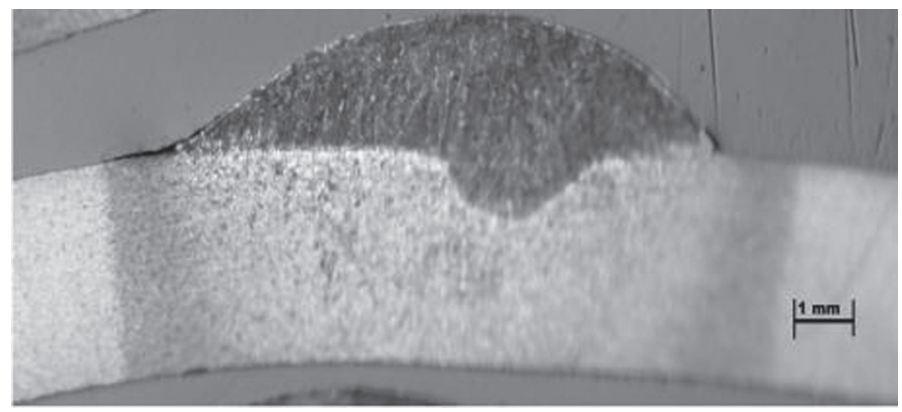

10G transferência de calor do arco para a peça.

Os valores das temperaturas determinadas na parede interna do tubo foram acima do limite recomendado pelo programa de análise desenvolvido pelo Instituto Battelle [6], o qual afirma que com o processo de soldagem com eletrodo revestido, a perfuração tende a ocorrer quando a temperatura ultrapassa $1260^{\circ} \mathrm{C}$. Em um trabalho mais recente, Begg [8] mostra que para os processos de soldagem semiautomáticos, a temperatura na parede interna do tubo pode ser maior, sem que ocorra perfuração.

Os resultados mostram que, apesar de a maior temperatura estar na parede interna do tubo, não ocorreu perfuração (Figura 8). Assim, os valores de temperatura na parede interna recomendados pelo programa de análise desenvolvido pelo Instituto Battelle são muito conservadores em relação à soldagem conduzida pelo processo MIG/MAG-P.

Na Figura 9 é apresentada a amostra " 4 G" com suas isolinhas de temperatura máxima e o ciclo térmico imposto durante a soldagem. De acordo com a tabela 10 a máxima temperatura na parede interna do tubo foi de $995^{\circ} \mathrm{C}$.

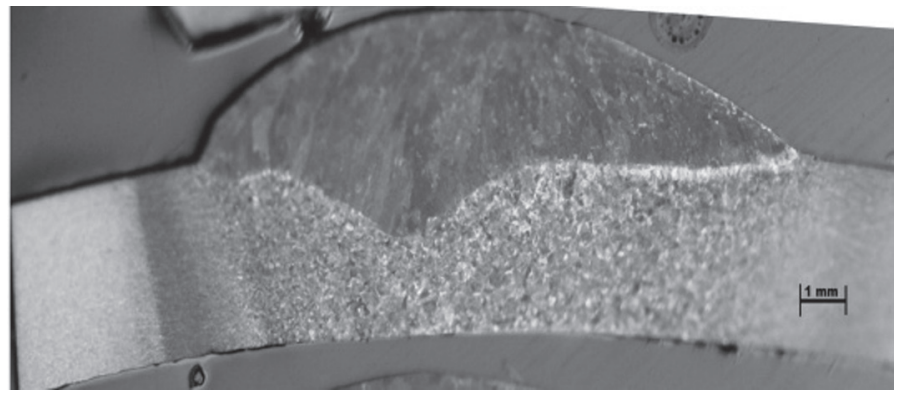

$2 \mathrm{G}$

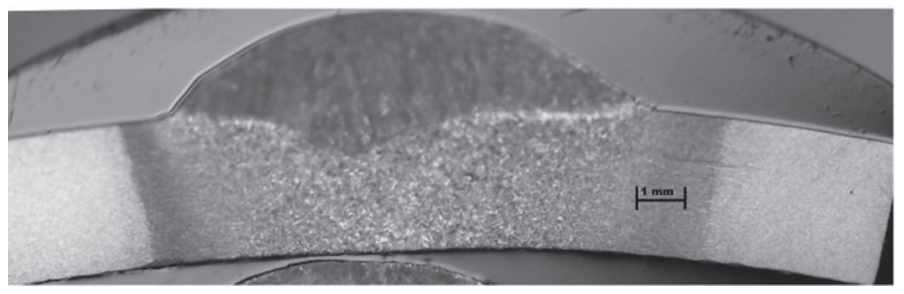

$7 \mathrm{G}$

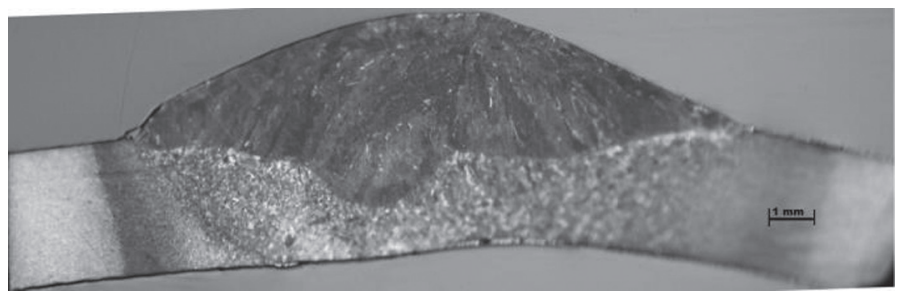

$12 \mathrm{G}$

Figura 8. Macrografias após a soldagem MIG/MAG-P empurrando a poça de fusão em tubos API 51 X70, com vazão de 40 1/ min. e pressão de 5 bar, utilizando-se tubos com espessura de $3,2 \mathrm{~mm}$. 
Tabela 10. Parâmetros de soldagem dados da temperatura na parede interna do tubo API-5L X70 com processo MIG/MAG em corrente pulsada e empurrando a poça.

\begin{tabular}{|c|c|c|c|c|c|c|c|c|}
\hline 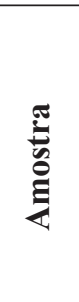 & 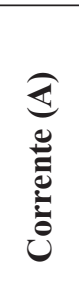 & 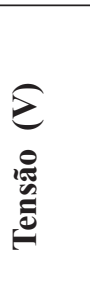 & 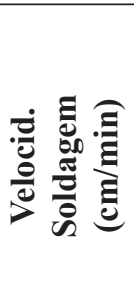 & 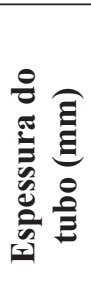 & 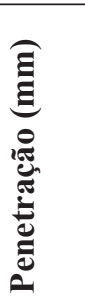 & $e_{0}^{e}$ & $\underset{\text { 国 }}{\underset{\Xi}{\Xi}}$ & 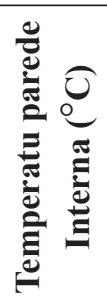 \\
\hline $1 \mathrm{G}$ & 150 & 27,4 & 30 & 3,12 & 1,58 & 35 & 2,15 & 1211 \\
\hline $2 \mathrm{G}$ & 150 & 25,9 & 23 & 3,23 & 1,28 & 30 & 2,04 & 1106 \\
\hline $3 G$ & 150 & 25,8 & 30 & 3,12 & 1,55 & 36,3 & 2,09 & 1130 \\
\hline $4 \mathrm{G}$ & 120 & 24,4 & 35 & 3,17 & 1,02 & 44 & 2,01 & 995 \\
\hline $5 \mathrm{G}$ & 180 & 28,4 & 25 & 3,22 & 1,62 & 27,2 & 2,2 & 1197 \\
\hline $6 \mathrm{G}$ & 150 & 27,1 & 30 & 3,17 & 1,52 & 35,7 & 2,21 & 1179 \\
\hline $7 \mathrm{G}$ & 120 & 25 & 25 & 3,20 & 1,24 & 30,7 & 1,32 & 1094 \\
\hline $8 \mathrm{G}$ & 150 & 26,9 & 37 & 3,17 & 0,95 & 33,2 & 2,13 & 997 \\
\hline $9 \mathrm{G}$ & 180 & 30,9 & 35 & 3,19 & 1,17 & 24 & 1,96 & 1044 \\
\hline $10 \mathrm{G}$ & 108 & 23,3 & 30 & 3,20 & 1,19 & 51,1 & 2,06 & 1086 \\
\hline $11 \mathrm{G}$ & 150 & 25,1 & 30 & 3,12 & 1,54 & 38 & 2,14 & 1059 \\
\hline $12 \mathrm{G}$ & 192 & 28,1 & 30 & 3,12 & 2,07 & 28,1 & 1,95 & 1304 \\
\hline $13 \mathrm{G}$ & 150 & 26 & 30 & 3,18 & 1,53 & 39,1 & 2,39 & 1213 \\
\hline
\end{tabular}
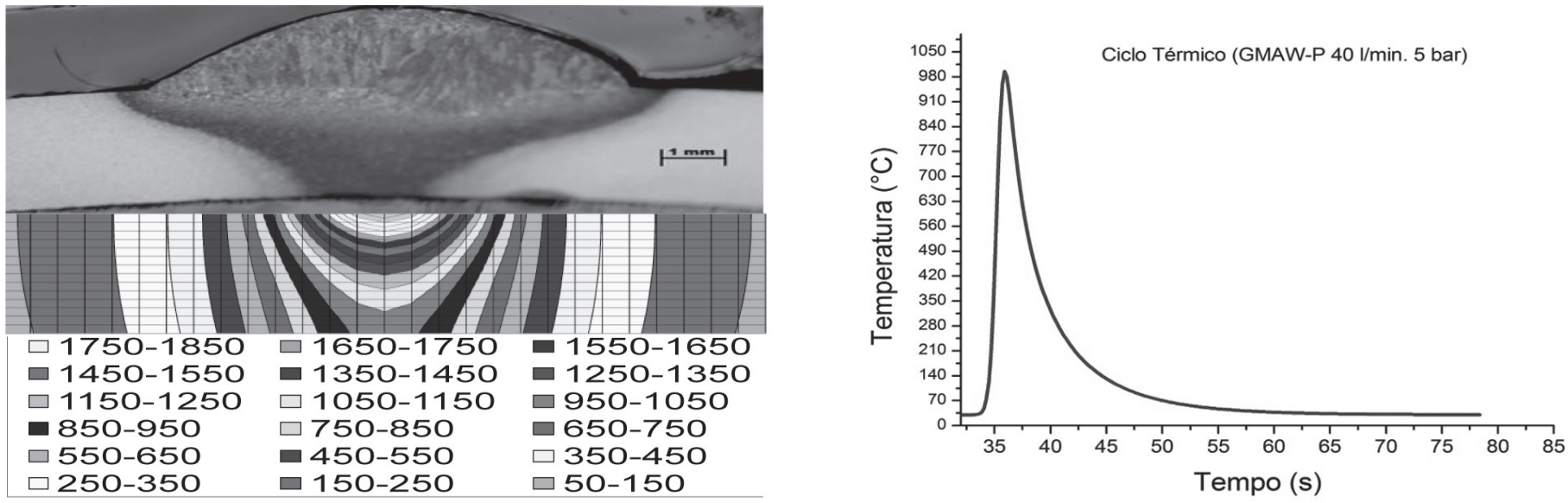

Figura 9. Amostra “4 G” com temperatura máxima para o ciclo térmico imposto durante a soldagem com MIG/MAG-P com vazão de $40 \mathrm{l} / \mathrm{min}$. de água e pressão de 5 bar, na parede interna do tubo.

\section{4 . Conclusões}

A partir da análise da literatura e dos resultados apresentados neste trabalho sobre a perfuração proveniente do arco elétrico no processo $\mathrm{MIG} / \mathrm{MAG}$, pode-se concluir que:

- Na soldagem MIG/MAG-P na condição empurrando a poça de fusão, mantidas todas as outras variáveis de soldagem fixas, a penetração do cordão de solda é a menor.

- O processo MIG/MAG-P apresentou os níveis de energia de soldagem para ocorrência da perfuração superior aos obtidos com o processo SMAW reportados na literatura.

- Para o intervalo pesquisado de velocidade de soldagem entre 25 a $35 \mathrm{~cm} / \mathrm{min}$. e de corrente entre 120 a 180 A percebeuse que: i) a penetração cresce com o aumento da corrente, constatação que é mais evidente para baixa velocidade de soldagem; ii) a penetração é máxima para uma velocidade de soldagem em torno de $30 \mathrm{~cm} / \mathrm{min}$.

- Mesmo apresentando alta temperatura na parede interna do tubo, para amostra $12 \mathrm{G}$, superior ao limite máximo determinado na literatura para SMAW, não ocorreu perfuração. 


\section{ReferênciasBibliográficas}

[1] WELDING HANDBOOK Volume1, Welding science and technology. American Welding Society, Miami - USA, 2004. $720 \mathrm{p}$.

[2] ADOLFSSON, S. at al. Automatic detection of burn-through in GMA welding using a parametric model. Mechanical Systems and Signal Processing. 2006. P. 633-651.

[3] PAES, Marcelo T.P. et al. Soldagem em operação de dutos e tubulações. I Encontro Técnico de Soldagem. Rio de Janeiro, Julho 2004.

[4] BRUCE, W. A. Weldingontoin-servicethin-wall pipelines. Final Report, Project PR-185-9908, Columbus/OH, 2000b. [5] PERES, G.E. at al. "Previsão da Perfuração na Soldagem em Operação pelo processo Eletrodo Revestido", Consolda 2007, Caxias do Sul.

[6] BRUCE, W. A. Overview of in-service welding research at EWI. First International conference on Welding onto Inservice Petroleum gas and Liquid pipelines. March 2000a, Wollongong Australia.

[7] KIEFNER, J. F. at al. Development of guidelines for repair and hot tap welding on pressurized pipelines. Final Report, Phase 1, to Repair and Hot Tap Welding group. Battelle Columbus Division. Columbus, OH September 1981.

[8] BEGG, Darren. Alternate Welding Processes for In-Service Welding. Final Report, BMT Group, April, 2009.

[9] SANTOS, L.A. Condução de Calor na Soldagem com

Pulsação Térmica. Tese de Doutorado, UFSC, Florianópolis, 2001. 145 páginas.

[10] SCOTTI, A.; PONOMAREV, V. Soldagem MIG/MAG:

melhor entendimento, melhor desempenho. Artliber Editora,

São Paulo, 2008.

[11] HERNÁNDEZ, R. G. Manual del Soldador, Asociación Española de Soldadura y Tecnologías de Unión, CESOL, 10 Ed., 2002. 